University of New Hampshire

University of New Hampshire Scholars' Repository

\title{
6-2013
}

\section{Near resonance acoustic scattering from organized schools of juvenile Atlantic bluefin tuna (Thunnus thynnus)}

Thomas C. Weber

University of New Hampshire, Durham, thomas.weber@unh.edu

Molly Lutcavage

University of Massachusetts - Amherst

Madeline L. Schroth-Miller

University of New Hampshire, Durham

Follow this and additional works at: https://scholars.unh.edu/ccom

Part of the Oceanography and Atmospheric Sciences and Meteorology Commons

\section{Recommended Citation}

T. C. Weber, M. E. Lutcavage, and M. L. Schroth-Miller, 'Near resonance acoustic scattering from organized schools of juvenile Atlantic bluefin tuna (Thunnus thynnus)', The Journal of the Acoustical Society of America, vol. 133, no. 6, p. 3802, 2013.

This Journal Article is brought to you for free and open access by the Center for Coastal and Ocean Mapping at University of New Hampshire Scholars' Repository. It has been accepted for inclusion in Center for Coastal and Ocean Mapping by an authorized administrator of University of New Hampshire Scholars' Repository. For more information, please contact Scholarly.Communication@unh.edu. 


\title{
Near resonance acoustic scattering from organized schools of juvenile Atlantic bluefin tuna (Thunnus thynnus)
}

\author{
Thomas C. Weber ${ }^{\text {a) }}$ \\ Center for Coastal and Ocean Mapping, University of New Hampshire, Durham, New Hampshire 03824 \\ Molly E. Lutcavage \\ Large Pelagics Research Center, Department of Environmental Conservation, University of Massachusetts \\ Amherst, Gloucester, Massachusetts 01931 \\ Madeline L. Schroth-Miller \\ Center for Coastal and Ocean Mapping, University of New Hampshire, Durham, New Hampshire 03824
}

(Received 30 July 2012; revised 23 March 2013; accepted 26 March 2013)

\begin{abstract}
Schools of Atlantic bluefin tuna (Thunnus thynnus) can exhibit highly organized spatial structure within the school. This structure was quantified for dome shaped schools using both aerial imagery collected from a commercial spotter plane and $400 \mathrm{kHz}$ multibeam echo sounder data collected on a fishing vessel in 2009 in Cape Cod Bay, MA. Observations from one school, containing an estimated 263 fish within an approximately ellipsoidal volume of $1900 \mathrm{~m}^{3}$, were used to seed an acoustic model that estimated the school target strength at frequencies between 10 and $2000 \mathrm{~Hz}$. The fish's swimbladder resonance was estimated to occur at approximately $50 \mathrm{~Hz}$. The acoustic model examined single and multiple scattering solutions and also a completely incoherent summation of scattering responses from the fish. Three levels of structure within the school were examined, starting with fish locations that were constrained by the school boundaries but placed according to a Poisson process, then incorporating a constraint on the distance to the nearest neighbor, and finally adding a constraint on the bearing to the nearest neighbor. Results suggest that both multiple scattering and spatial organization within the school should be considered when estimating the target strength of schools similar to the ones considered here.
\end{abstract}

(C) 2013 Acoustical Society of America. [http://dx.doi.org/10.1121/1.4802646]

PACS number(s): 43.30.Ft, 43.30.Sf [APL]

Pages: $3802-3812$

\section{INTRODUCTION}

Although acoustic scattering from aggregations of fish containing swimbladders at low- to mid-frequencies (i.e., near swimbladder resonance) has been examined both theoretically and experimentally for at least the last half century (e.g., Weston, 1967; Holliday, 1972), the relative positioning of fish within an aggregation is often considered in a mostly ad hoc manner due to the difficulty in experimentally observing, or accurately modeling, the locations of individual fish. In this work, we examine the modeled acoustic backscatter from a school of juvenile Atlantic bluefin tuna (Thunnus thynnus) for which the spatial organization of fish and the school shape are well known, having been empirically derived from measurements made using aerial imagery and a high frequency multibeam echosounder (MBES). The term school is used to describe a specific type of aggregation where, according to the definition used by Pitcher and Parish (1993), an aggregation is simply a group of fish, whereas in a school, the fish are closely spaced, polarized, of similar size, and act with some sort of synchronicity. Of particular interest in this work is whether the spatial organization of fish within the school has any non-negligible effect on the acoustic backscatter from the school and if the school target

\footnotetext{
a) Author to whom correspondence should be addressed. Electronic mail: weber@ccom.unh.edu
}

strength is adequately considered as an incoherent summation of the scattered waves from individual fish or whether a higher fidelity model that includes either singly or multiply scattered waves is important to consider.

One of the earliest investigators of the acoustic effects of the spatial organization of fish was Weston $(1966,1967)$, who considered line and plane arrays of fish the swimbladders of which were the dominant scattering mechanism. Feuillade et al. (1996) followed up on Weston's early work, simulating acoustic scattering from fish arranged in "basic school units" with average fish locations at the corners and center of a cube of variable size and with deviations from the average fish location being drawn from a normal distribution of variable standard deviation. Diachok (1999) considered the attenuation through an aggregation of sardines, examining school resonances in the context of an average spacing between fish as well as multiple resonances due to changes in fishing spacing according to whether the fish were located within a densely populated school nucleus or on the more sparsely populated periphery. Hahn (2007) examined hypothetical aggregations of randomly distributed fish, constraining the average spacing between fish with a wide range of packing densities. Andrews et al. (2011) compared the modeled backscatter from aggregations of Atlantic herring arranged with either fully randomized fish positions or with a similar lattice structure to that used by Feuillade et al. (1996). Collectively, these authors suggest that group 
resonances may exist for sufficiently dense aggregations of fish where the resonance frequency for an aggregation of fish is lower than that which would be predicted by incoherent fish scattering models, analogous to the collective bubble plume oscillations identified as a source of low frequency ambient noise in the ocean (Carey and Bradley, 1985; Carey and Fitzgerald, 1987; Prosperetti, 1988). However, these types of coherent scattering effects are not expected to be an important consideration for all types of schools. For example, Andrews et al. (2011) concluded that these effects were negligible for a long-range acoustic experiment (see Gong et al. 2010) with aggregations of herring in the Gulf of Maine for which the average volumetric fish density was estimated to be $0.05 \mathrm{fish} / \mathrm{m}^{3}$, providing a bound on what "sufficiently dense" means at least in the context of the Atlantic herring considered in that study. The work of Weber et al. [2007, Eq. (39)] suggests that in addition to considering the density of scatters, it is also important to consider both the average scattering strength of an individual as well as the size of the aggregation under the premise that coherent scattering effects will be more pronounced when multiple scattering effects are non-negligible.

If the spatial organization of fish (i.e., schooling behaviors) within an aggregation is important for acoustic scattering predictions, then Atlantic bluefin tuna (ABFT) are an interesting species to consider. ABFT have been observed to exhibit schooling behaviors (Lutcavage and Kraus, 1995; Lutcavage et al., 1997a; Lutcavage et al., 1997b), perhaps for increased hydrodynamic efficiency, for feeding benefits, or for some other unknown benefit (Partridge et al., 1983). They exhibit a variety of schooling geometries at the sea surface including parabolic or straight line formations, cartwheels (swimming in a circle), surface sheets, and dome shapes (Lutcavage and Kraus, 1995). ABFT are also slightly denser than seawater and utilize a gas-filled swimbladder to maintain swimming depths at slow speeds (Magnuson, 1973).

ABFT are found in much of the North Atlantic at depths between the surface and $1000 \mathrm{~m}$. For the size of fish examined in this paper (approximately $1.5 \mathrm{~m}$ ), ABFT travel with an average speed of approximately 3-4 knots on feeding grounds and 8 knots during migration (Mather et al., 1995; Lutcavage et al., 2000; Brill et al., 2002). Electronic data loggers and sonic tracking have provided extensive fisheryindependent information on vertical behavior of ABFT. Juvenile and adult ABFT spend $>80 \%-90 \%$ of their time in the top 10-20 m, especially in the Gulf of Maine, their foraging grounds (Lutcavage et al., 2000; Galuardi et al., 2010, Brill et al., 2002). Although juveniles have been observed to occasionally dive more deeply, to hundreds of meters, on the continental shelf, they are usually located between the surface and thermocline (Galuardi and Lutcavage, 2012), consistent with our sonar observations. Although the explicit behavior of individuals in schools of different sizes/behaviors is not completely documented, schooling behavior has been described from aerial surveys and direct observations of juveniles and adults in the Gulf of Maine, VA, and the Bahamas (e.g., Lutcavage and Kraus, 1995; Lutcavage et al., 1997a; Lutcavage et al., 1997b). Packing density (e.g., nearest neighbor distance) appears to be related to fish size not behavior or number of individuals in a school. The conformation and number of individuals in schools change, but packing density or nearest neighbor distances do not change to any extent. Partridge et al. (1983) examined aerial photographs of schools containing between 2 and 79 large (2.4-2.9 m) ABFT in what they considered to be twodimensional schools at the sea surface. Within these schools, they found nearest neighbor distances (estimated from the distance between one nose and another) to be between 1.5 and 2 body lengths, and for schools containing 15 or more fish that were not arranged in a parabola or line, they observed the most common bearing to a nearest neighbor to be either $45^{\circ}$ or $135^{\circ}$.

In the work described in this paper, we examine a dome-shaped school containing an estimated 263 juvenile ABFT, in which each individual fish is an estimated $1.5 \mathrm{~m}$ long. Using aerial imagery, individual fish are identified and the spatial organization of the ABFT within the school for up to 6 nearest neighbors is examined (Sec. II). The aerial imagery collapses the school onto a two dimensional plane, possibly missing fish that are deeper than a few meters water depth (depending on the optical clarity of the water) or fish that are obscured by other fish. The nearest neighbor distance for the fish collapsed onto a two-dimensional plane is estimated to be 0.5 body lengths. To determine the average vertical cross-section of the school, side-looking $400 \mathrm{kHz}$ MBES data that were collected concurrently with the aerial imagery are examined (Sec. III). Together, the empirically derived school characteristics from the aerial imagery and the MBES are used to generate simulated schools of ABFT (Sec. IV). Schools with varying levels of spatial organization are simulated: A Poisson distributed (i.e., no spatial organization) group of fish located within the school boundaries, schools, where a nearest neighbor distance derived from the empirical observations is imposed on the spatial organization of fish, and schools where both a nearest neighbor distance and a relative bearing are imposed. These school models are used to seed an acoustic simulation that examines the continuous wave $(\mathrm{CW})$ backscatter from the schools at frequencies between 10 and $2000 \mathrm{~Hz}$ (Sec. V). The acoustic scatter from individual fish is considered only in terms of the swimbladder response. To isolate the effects of spatial organization within the school on acoustic backscatter, the acoustic simulation is performed in an idealized setting: Far from the ocean surface or bottom boundaries and in an isovelocity environment with results shown in Sec. VI. The acoustic model examines both the single scattering and a full multiple scattering solution.

\section{AERIAL PHOTOGRAPHY}

Aerial photography was collected from schools of juvenile ABFT using a hand-held Canon EOS Rebel T1j on a commercial spotter plane in similar fashion to previous ABFT aerial surveys (e.g., Lutcavage and Kraus, 1995; Lutcavage et al., 1997b), during a flight conducted on 16 August 2009 over Cape Cod Bay, MA. A typical altitude for collecting the aerial imagery was $213 \mathrm{~m}(700 \mathrm{ft})$, and at 
(a)

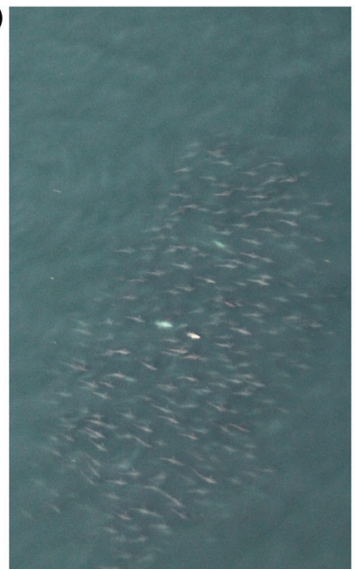

(b)

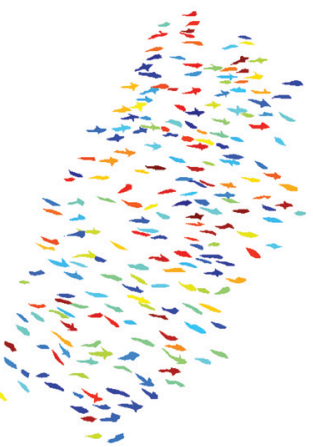

FIG. 1. (a) Raw aerial imagery showing a school of ABFT; (b) manually classified individual ABFT with randomly assigned colors indicating unique fish.

this altitude, individual ABFT can be identified in the aerial photographs [Fig. 1(a)]. These data were collected near $42.0^{\circ} \mathrm{N} / 70.3^{\circ} \mathrm{W}$ in a water depth of approximately $40 \mathrm{~m}$. Each image was classified manually by tracing the outlines of each fish [Fig. 1(b)] to estimate the approximate horizontal shape of the visible portion of the school (an ellipse with major and minor axes of 31 and $13 \mathrm{~m}$, respectively, as will be discussed), and to determine whether any spatial organization between individual ABFT was apparent within the school. The aerial imagery data used in this paper, which are considered to be typical of the dome shaped juvenile ABFT schools that were present during several days of ABFT surveying in Cape Cod Bay over the course of the experiment, consist of 11 consecutive images collected between 19:21:31 and 19:21:35 GMT (Fig. 2) under calm surface conditions.
The fish imaged in this school were estimated to weigh between 57 and $79 \mathrm{~kg}(125-175 \mathrm{lb})$ by the commercial spotter pilot. Using the length-weight relationship given by Restrepo et al. (2010) this corresponds to a body length between 1.4 and $1.6 \mathrm{~m}$.

For each classified fish, both a "center of mass" (assuming equal weighting within the outlined representation of the fish) and a fish orientation (the orientation of the longest axis of the fish) within the local coordinates of the image are calculated. The distance and bearing (relative to the fish orientation) to the nearest neighbor is calculated with lengths measured in fish body lengths. Because these fish are assumed to be approximately the same length, based on observations from the commercial spotter pilot as well as sizes of individuals in bluefin schools caught by purse seine (Lutcavage, unpublished data), the body length is taken to be the longest observed length within the school, with shorter observed lengths attributed to limited optical clarity in the water. For the purposes of this work, any bias error in the average fish length is thought to be small compared with the unknown error in estimates of swimbladder size.

Both nearest neighbor distances (NND) and nearest neighbor relative bearings (NNRB) were estimated for all observed individuals in 11 sequential photographs of the same school (Fig. 2) with a total 2586 observed individuals. Probability density function (pdf) estimates (Fig. 3) of NND shows that the preferential distance between fish observed in the aerial imagery is 0.48 body lengths. It is important to note that the aerial imagery projects any three-dimensional structure within the school onto a two-dimensional plane, and so the nearest neighbor distance in three dimensions is likely to be greater. The pdf representing the NNRB show that the nearest neighbor is unlikely to be located either
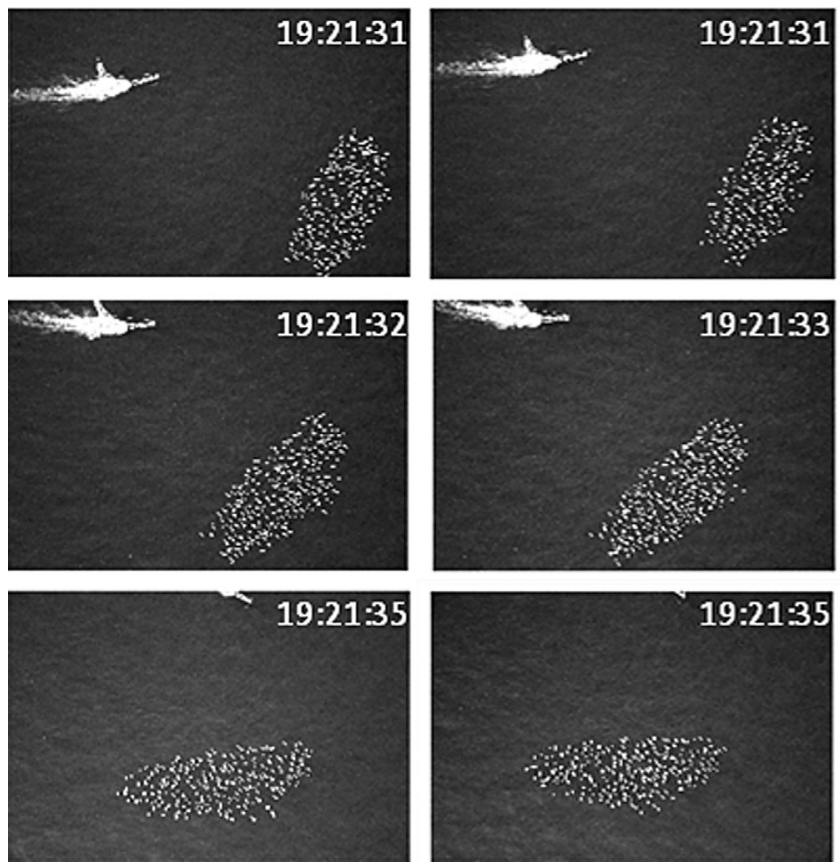
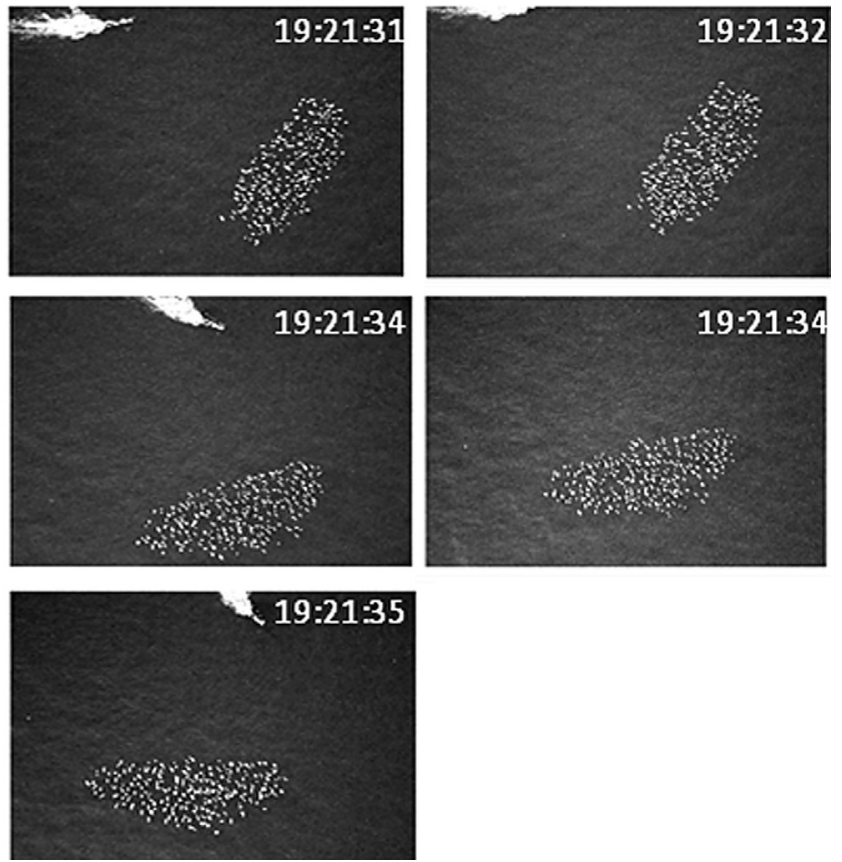

FIG. 2. Eleven consecutive aerial images of a juvenile Atlantic bluefin school. In each image. the tuna have been enhanced by using the manual classification as a mask. 

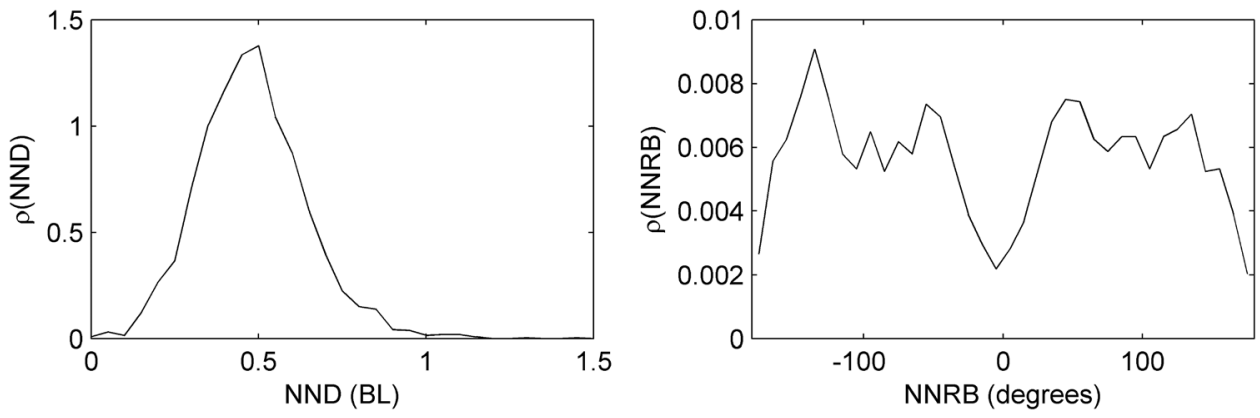

FIG. 3. Pdf of nearest neighbor distance, NND, calculated in terms of body lengths (BL) (left) and pdf of nearest neighbor relative bearings, NNRB, in degrees (right). Observations of 2586 individual ABFT from 11 consecutive images were used to generate these empirical pdfs. directly in front or behind a juvenile ABFT, and that there may be some preference for nearest neighbors located near $\pm 45^{\circ}$ and $\pm 135^{\circ}$.

To examine the combined dependence of nearest neighbor distance and relative bearing for multiple neighbors, twodimensional histograms were generated for the closest near neighbor, the second closest near neighbor, and so on (Fig. 4, upper row). A two-dimensional (2D) sliding mean (a 2D uniformly weighted window that was $30^{\circ}$ by 0.15 body lengths) was used to smooth the data (Fig. 4, lower row) to help elucidate any structure within the school. The results of the nearest neighbors analysis show that it is not uncommon to have six or more fish within one body length of each other (as projected onto a two-dimensional plane; the average number of neighbors within one body length is estimated from these data to be 6.5) with the nearest neighbor most often located at a distance of 0.48 body lengths and at a relative bearing of either $\pm 45^{\circ}$ or \pm 135 . The pdf's describing the second to sixth nearest neighbors also appear to show some increased probability at localized bearings as well. To determine whether the apparent preferred bearings to neighboring fish are statistically significant (or, conversely, are artifacts of the low-pass filtering), a Kolmogorov-Smirnov test was used to examine the hypothesis that the bearings for each of the nearest neighbors (first through sixth) fit a uniform distribution. This hypothesis was rejected at the 5\% significance level for the nearest neighbor, as expected, and also, unexpectedly and for unknown reasons, for the sixth neighbor. The hypothesis
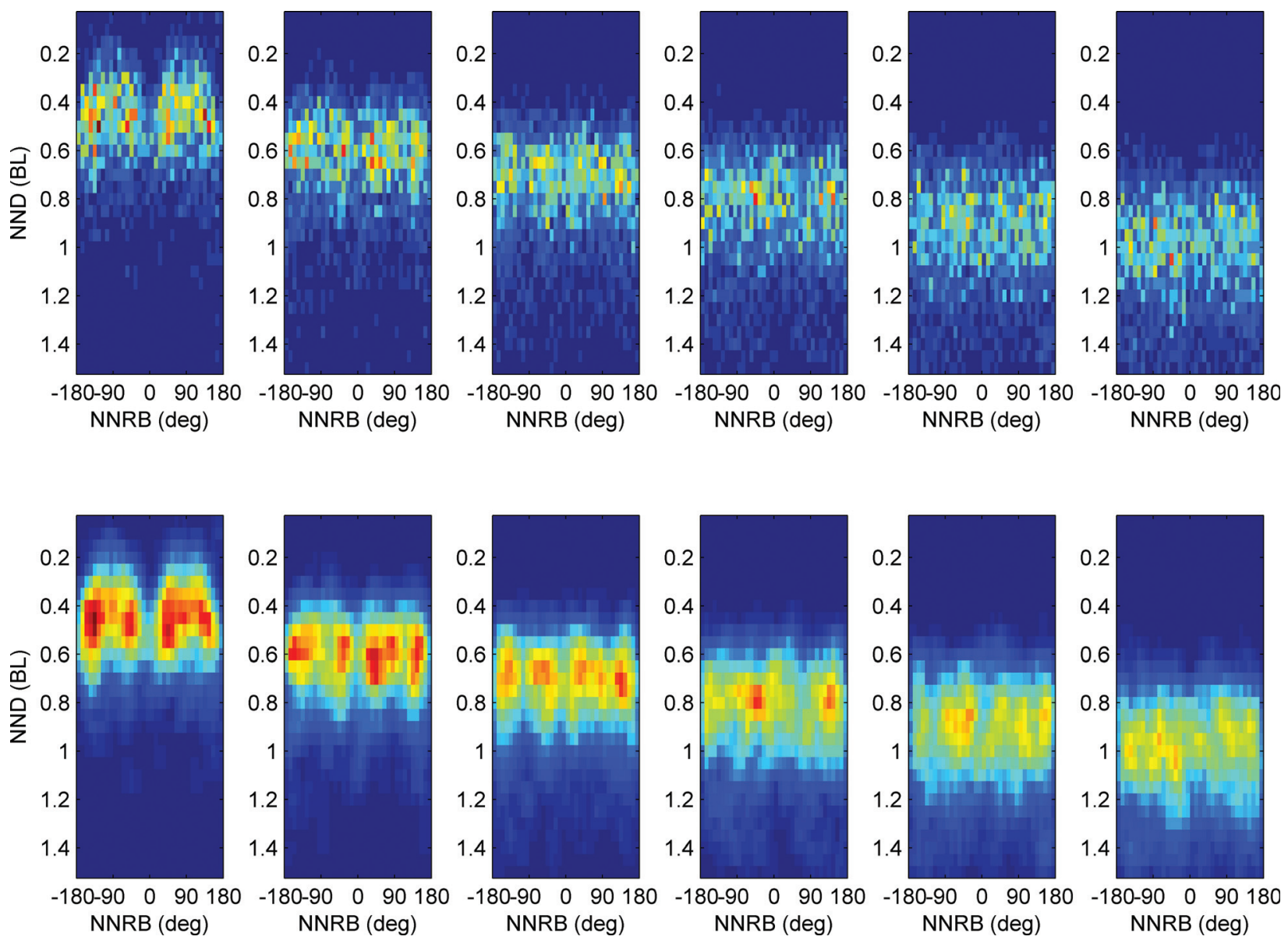

FIG. 4. Two-dimensional histograms describing the positional dependency of the nearest neighbors of an individual tuna, plotted as a function of NND in body lengths and NNRB in degrees. The first column represents the closest near neighbor, the second column represents the next closest near neighbor, and so on. The top row shows the raw histograms, and the bottom row shows low-pass filtered versions of the histograms. Color represents the amplitude of the pdf with red being the highest and blue being the lowest, ranging from 0 to $0.008 \mathrm{deg}^{-1} \mathrm{~m}^{-1}$ in the top row and 0 to $0.005 \mathrm{deg} \mathrm{m}^{-1}$ in the bottom row. 
was accepted for each of the other neighbors (second to fifth) at the 5\% significance level. Apart from the unexplained sixth neighbor, this result indicates that the tuna can be adequately modeled by considering only the spatial correlations between pairs of fish. When the low-passed filtered two-dimensional pdf for the nearest neighbor (Fig. 4, bottom row) is resampled with replacement to generated simulated distributions of fish within the school, the re-sampled fish show correlations between neighbors that are qualitatively similar to that which was observed.

The aerial photographs are also used to estimate the horizontal shape of the school. A convex hull is calculated for the first six images shown in Fig. 2, which have a similar camera viewpoint, using the locations (centers of mass) of the individual fish resulting from the manual classification of the images. Both the perimeter and the area of the convex hull are then calculated, and the ratio of the perimeter to the square root of the area is calculated to provide a non-dimensional parameter describing the school shape. This shape parameter monotonically increases from 4.0 to 4.2 (note that a circle has a shape parameter of 3.54) over the six sequential photographs, due either to actual changes in the school horizontal shape or distortion related to the camera and its angle of view. In the present study in which the intra-school fish spacing is thought a priori to be most important when examining the scattering statistics, the horizontal school shape is simply approximated as an ellipse with a shape parameter equal to 4.1, the average over the six images.

Within the school, the observed number of fish in each of the 11 photographs varied from 215 to 263 individuals with the variation attributed to an unknown combination of occlusion, optical clarity of the water, and relative position of the plane to the fish. The number of fish within the school is believed to be constant over the 4-s time interval in which the photographs were taken, and so the total number of fish within the school is estimated to be 263. This number may be biased low due to unobserved fish.

\section{SIDE-LOOKING MBES DATA}

The aerial imagery provides a useful synoptic view of the juvenile ABFT schools but collapses the three dimensional school onto a two-dimensional surface. To provide the vertical dimension for the juvenile ABFT schools, a $400 \mathrm{kHz}$ Reson 7125 MBES was pole mounted on a fishing vessel that was approximately $10 \mathrm{~m}$ long. The depth of the co-located transmit and receive arrays was approximately $1 \mathrm{~m}$. This MBES uses a Mills cross array topology to form 256 beams between $\pm 64^{\circ}$ with a nominal angular resolution of $1^{\circ} \times 0.5^{\circ}$ (horizontal and vertical $3 \mathrm{~dB}$ beamwidths) and was oriented so that its center beam was pointed horizontally in the vertical plane and approximately $45^{\circ}$ off the starboard bow. The MBES transmitted a $100 \mu$ s pulse length at a rate of $3.8 \mathrm{ping} / \mathrm{s}$. Using the $3 \mathrm{~dB}$ beam widths and the pulse length, the spatial resolution of the MBES center beam at a range of $50 \mathrm{~m}$ is approximately $0.08 \mathrm{~m}$ in the direction parallel to the beam, $0.9 \mathrm{~m}$ horizontally, and $0.4 \mathrm{~m}$ vertically.

To collect vertical cross-sections of the ABFT schools with the MBES, the vessel was guided to the school by the pilot collecting the aerial imagery. After acquiring the ABFT school on the sonar, the school was tracked for as long as possible. It was difficult to interpret the effect that the vessel (or its running motor) had on the fish except when the vessel was very close $(<20 \mathrm{~m})$ to the fish in which case the fish dove and were lost visually.

An example image from the MBES is shown in Fig. 5. Depending on the range to the school, the tuna are sometimes resolved as individual targets as appears to be the case in Fig. 5. Weather conditions were necessarily calm for the pilots to photograph the ABFT schools, and the smooth surface results in multipath reflections that cause an "image" school to appear above the sea surface. Self-noise, suspected to be electrical interference in the MBES receiver, appears in the image as a noisy center beam.

The MBES data were processed on a ping by ping basis to isolate the backscatter from the ABFT using a constant false alarm rate (CFAR) approach with a threshold chosen on a pixel by pixel (i.e., each range/angle bin) noise history of data with no ABFT present, similar to the method described by Weber et al. (2009). After thresholding, both the obvious outliers and "image" fish (reflections arriving via the sea surface) were manually removed, and the final result was considered to be a representation of a school cross section.

To determine an average vertical cross-sectional shape for each ping, a convex hull was defined for the detections

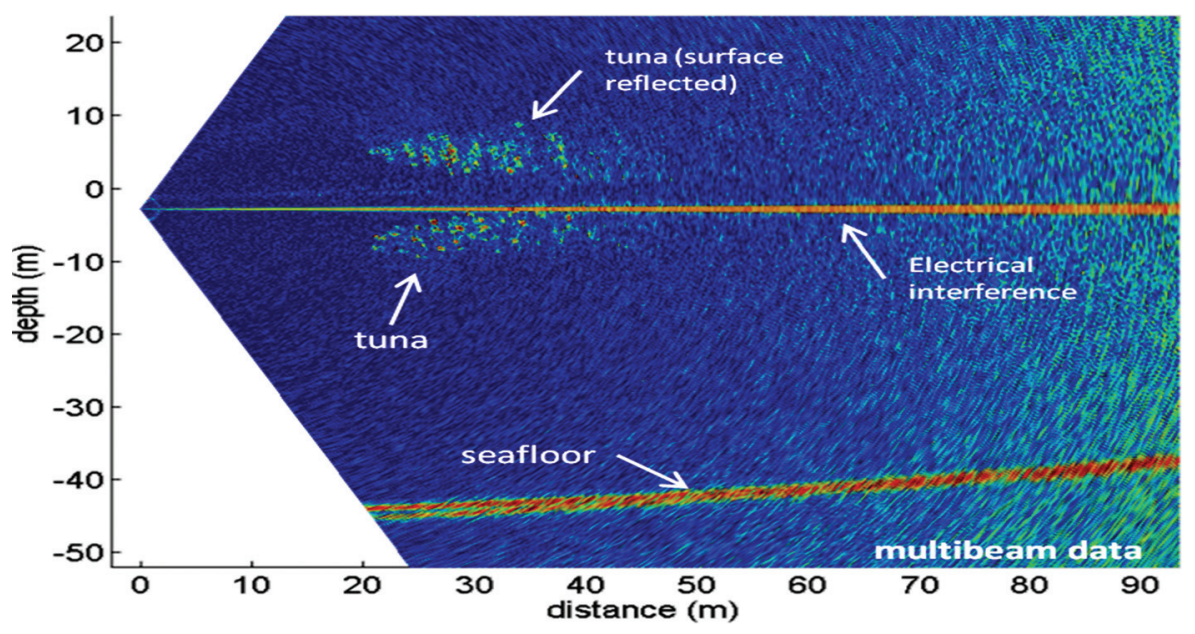

FIG. 5. Data collected from a single ping of a side-looking $400 \mathrm{kHz}$ MBES, showing a vertical cross-section of a juvenile ABFT school. The "image" school due to acoustic paths reflected from the sea surface were excluded from this work. 
(i.e., the remaining pixels after the thresholding, despeckling, and manual cleaning operations). Four parameters were derived from the convex hull and are shown as a function of ping number in Fig. 6, corresponding to MBES data collected from the same school shown in Fig. 2. Between pings 8 and 135 (approximately $0.5 \mathrm{~min}$ ), the distance between the vessel and the school (as imaged by MBES) decreased nearly linearly from 65 to $30 \mathrm{~m}$. The school height during the record is nearly constant around $9 \mathrm{~m}$ (with depths ranging from approximately $1-10 \mathrm{~m}$ ) with a rapid increase between pings 10 and 20 and a rapid decrease after ping 120 and a suggestion of a weak increase in height between pings 20 and 80. The school area and maximum length steadily increase from ping 10 to 100 with the latter increasing from slightly more than $10 \mathrm{~m}$ to approximately $30 \mathrm{~m}$ and then begin to steadily decrease for the duration of the record. These dimensions are in qualitative agreement with the aerial imagery containing both the $10 \mathrm{~m}$ fishing vessel and the school (Fig. 2), noting that the $10 \mathrm{~m}$ size is measured from stem to stern and does not include the "pulpit" extending several meters out from the vessel's bow. The shape parameter shows a general increasing trend between pings 20 and 100 , and a decreasing trend thereafter.

Taken together, the parameters extracted from the MBES describe a scenario in which the MBES beams are "sweeping" across the school as the vessel tracks the ABFT school on the surface, collecting cross sections of the school at different orientations along the way. Pings 11-30 were collected between 19:21:34.23 and 19:21:39.5 GMT, during which time the aerial imagery (Fig. 2) suggests that the vessel was oriented relative to the school in such a way that the shortest axis of the school was imaged. The average length [Fig. 6(b)] during this time is $13 \mathrm{~m}$. The increasing school area and length suggest that the orientation between the vessel and the school changed so that by pings $95-100$, the long axis of the school was being imaged. Assuming that the horizontal shape of the school was described by an ellipse the short axis of which was $13 \mathrm{~m}$ with a shape parameter of 4.1 (from Sec. II), the long axis of the school would be approximately $31 \mathrm{~m}$, consistent with the lengths observed during pings 95-100. The school height is estimated to be $9 \mathrm{~m}$, the average height between pings 30 and 120 and assuming that MBES is ensonfying the middle of the school during this time.

\section{SCHOOL MODELS}

The aerial imagery and the MBES data are consistent with an ellipsoid shaped school the horizontal major and minor axes of which are 31 and $13 \mathrm{~m}$, respectively, and the vertical axis of which is $9 \mathrm{~m}$. School shape parameters derived from both the aerial photographs and the MBES were used to simulate the shape of a juvenile ABFT school. This task is somewhat complicated by the lack of accurate knowledge of the orientation of the school with respect to the MBES, and so we assume a simple shape consistent with the MBES and aerial observations, acknowledging that it is only an approximate school shape. The school boundary is modeled as a tri-axis ellipsoid, with a maximum horizontal length (major axis) of $31 \mathrm{~m}$, a minor horizontal axis of $13 \mathrm{~m}$, and a maximum vertical dimension of $9 \mathrm{~m}$. A vertical slice through the major axis of this modeled ellipsoid would result in a cross section the shape parameter of which was 4.6 in close agreement with the MBES observations (see, for example, the maximum length, school height, and shape parameter at ping number 100). A vertical slice through the minor axis of this ellipsoid results in a shape parameter of 3.6, somewhat lower than any observation with the MBES. This may indicate that the shortest horizontal dimension of the school was imaged by the MBES away from school center where the vertical height of the school was smaller. (a)

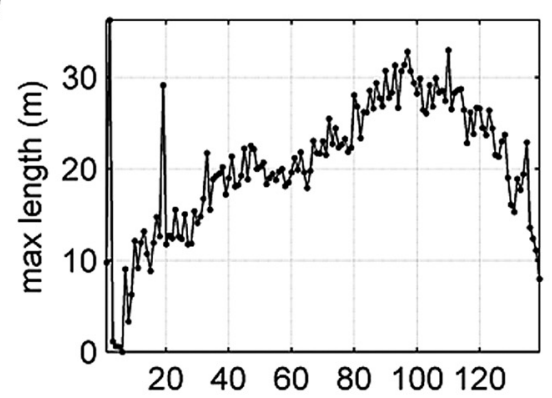

(c)

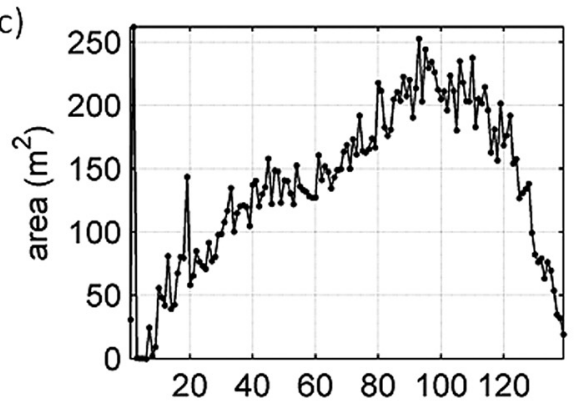

(b)

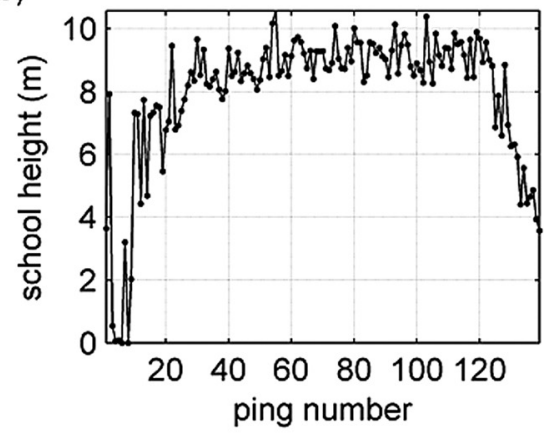

(d)

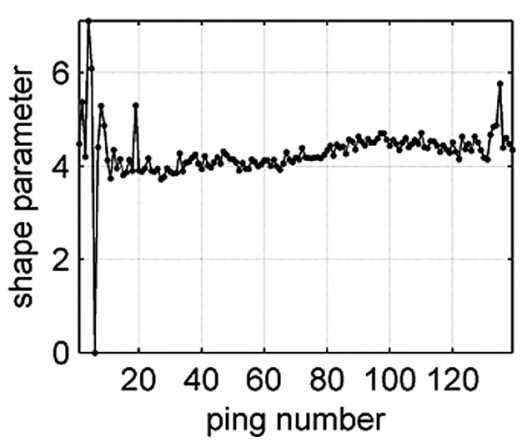

FIG. 6. Parameters describing the juvenile ABFT school derived from the MBES data, including (a) maximum length of the school; (b) school height; (c) vertical cross sectional area; (d) shape parameter. 
The fish locations within each school were drawn from random distributions of locations using three varying levels of spatial order: No spatial order (Poisson distributed), a nearest neighbor criterion accounting for spatial correlation in range only, and a nearest neighbor criteria governing both range and relative bearing. When accounting only for nearest neighbor distance and not relative bearing, the location of each fish was found by repeated draws from a uniform distribution of locations within the school, with retention of the first fish whose distance (in the horizontal plane) from each other previously drawn fish was at least one-half body length. To account for both range and relative bearing, a random draw with replacement was made from the smoothed empirical pdfs [Fig. 4(b)]. In all cases, the vertical distribution of the fish followed a uniform distribution over the local vertical extent of the school.

Within the school, each fish is replaced by a monopole resonator simulating a swimbladder, which is expected to dominate the acoustic response at low- to mid-frequencies (this is assumed to be true up to $20 \mathrm{kHz}$ in this work). Although the swimbladder of individual tuna is highly variable in both shape and size (Gibbs and Collette, 1967), no metrics describing this variability are available in the published literature. For the purposes of this work, a $150 \mathrm{~cm}$ forklength (FL) ABFT is assumed to have a swimbladder volume of 1100 cubic centimeters (cc) based on those measured in yellowfin tuna (Thunnus albacores) (Schaefer and Oliver, 2000). Despite the possible difference between species, this is thought to be a reasonable approximation given that both species would have needed to develop a swimbladder for the same mechanical reasons outlined by Magnuson (1973). In addition to uncertainty about the distribution of swimbladder sizes for the tuna observed within the school, there is also an unknown depth dependency in the swim bladder size and acoustic response for the fish distributed over the observed depths $(1-10 \mathrm{~m})$. ABFT are physoclists (they have a closed swimbladder), and as such have a swimbladder resonance frequency that is expected to vary as the square root of the ambient pressure, about a $40 \%$ variation over the depth variation observed in the school (Simmonds and Maclennan, 2005). This depth dependence is expected for fish that have adapted to depth, however, and if the tuna are rapidly changing depth within the school, the swimbladder resonance frequency is expected to vary more widely, following a $(1+z / 10)^{5 / 6}$ relationship with depth, $z$, or about a $75 \%$ variation for the ABFT observed here. Curiously, Bertrand et al. (1999) were not able to discern a depth dependency in the target strength of yellowfin tuna for depths up to $100 \mathrm{~m}$, although they conducted their study well above the swimbladder resonance frequency and were likely influenced strongly by the swimbladder orientation.

In this work, the acoustic behavior of the swimbladder is treated very simply, primarily because data describing the actual swimbladder behavior are lacking. The ABFT are assumed to have a length variation following a Gaussian distribution with a $7.5 \mathrm{~cm}$ standard deviation, resulting in a standard deviation in swimbladder volume of $200 \mathrm{cc}$. The target strengths for individual tuna (swimbladder) of these sizes were estimated using the model described by Love
(1978) evaluated at ambient pressure. The resulting swimbladder resonance frequencies very between approximately 45 and $65 \mathrm{~Hz}$ with a standard deviation slightly greater than $3 \mathrm{~Hz}$. It is possible that this underrepresents the true variability in swimbladder resonance, but information describing the true variable is not available for the ABFT studied here.

\section{ACOUSTIC SIMULATION}

The simulated schools are used to seed an ideal environment with monopole scattering centers with the assumption that the boundaries are sufficiently far away to be negligible and in an isovelocity water column. This is a departure from the observations reported here where the fish were observed close to the sea surface, suggesting that Lloyd-mirror effects would likely play a significant role, and is an attempt to isolate any effects related to the organization of the fish within the school from local environmental conditions. Only backscatter from the school is considered, using an omni-directional source of $\mathrm{CW}$ waves at horizontal distance of $1 \mathrm{~km}$ from the school with a co-located omni-directional receiver. Both source and receiver are placed at the same depth as the school center. Frequencies between 10 and $2000 \mathrm{~Hz}$ are examined, covering the range of an individual swimbladder resonance.

Two coherent backscatter models are examined. In the first model, the fish are assumed to scatter acoustic waves independently of each other (that is, the acoustic signal at the receiver from each fish is calculated as if no other fish were present)

$$
p_{s s}=\sum_{i=1}^{263} s_{i} p_{o, i} G\left(r_{r}, r_{i}\right),
$$

where the subscript $s s$ indicates the singly scattered solution, $p_{o, i}$ is the incident pressure field at each swimbladder, $s_{i}$ is the complex scattering amplitude of the $i$ th swim bladder, and $G$ is the free-field Green's function between the receiver located at position $r_{r}$ and the fish located at position $r_{i}$ given by

$$
G\left(r_{r}, r_{i}\right)=\frac{\exp \left(-j k\left|r_{r}-r_{i}\right|\right)}{\left|r_{r}-r_{i}\right|}
$$

where $k$ is the acoustic wavenumber.

For the single scatter solution, $p_{o, i}$ accounts only for the radiated field from the source and assumes that any scattered contributions from nearby swimbladders are negligible; thus $p_{o, i}=A G\left(r_{r}, r_{i}\right)$ where $A$ is the source amplitude. The complex scattering amplitude of the swimbladder is assumed to be the same for a gas bubble acting as a monopole radiator (Clay and Medwin, 1977)

$$
s_{i}=\frac{a \exp (-j k a)}{\omega_{o}^{2} / \omega^{2}-1-j \delta},
$$

where $a=\left(3 v_{s b} / 4 \pi\right)^{1 / 3}$ is assumed to be the effective swimbladder radius based on its volume $v_{s b}, \omega_{o}$ is the resonance frequency of the fish in radians per second, and $\delta$ is a 
damping constant. Both the resonance frequency and damping constant are calculated following the formulation given by Love (1978) assuming the swimbladder to be filled with air with a density of $1.3 \mathrm{~kg} / \mathrm{m}^{3}$ and a sound speed of $340 \mathrm{~m} / \mathrm{s}$, sea water and fish flesh densities of $1000 \mathrm{~kg} / \mathrm{m}^{3}$ and $1050 \mathrm{~kg} /$ $\mathrm{m}^{3}$, respectively, a viscosity parameter of $50 \mathrm{~Pa} \cdot \mathrm{s}$, and a surface tension of $1000 \mathrm{~N} / \mathrm{m}$. The fish target strength is estimated assuming the fish are at atmospheric pressure. This model yields a target strength for an individual $1.5 \mathrm{~m}$ long ABFT of $-2.6 \mathrm{~dB}$ at the resonance frequency of $53 \mathrm{~Hz}$. The variation in fish length assumed in the model causes the average target strength for an individual to be approximately $3 \mathrm{~dB}$ lower.The second model incorporates multiple scattering in the manner first described by Foldy (1945)

$$
p_{m s}=\sum_{i=1}^{263} s_{i} p_{o, i}^{i} G\left(r_{r}, r_{i}\right)
$$

where the incident pressure accounts both for the incident pressure from the source as well as the contributions from the other tuna within the school

$$
p_{o, i}^{i}=p_{o, i}+\sum_{j=1 ; j \neq i}^{263} s_{j} p_{o, j}^{j} G\left(r_{i}, r_{j}\right) .
$$

In both cases, absorption through the water column is neglected, and the school target strength is calculated accounting for source strength and two-way spherical spreading using

$$
T S=20 \log _{10}\left|\frac{p}{A} r^{2}\right|,
$$

where $p$ is either $p_{s s}$ or $p_{m s}$ depending on whether the single scattered or multiple scattered target strength is being estimated.

For reference, the school target strength is also calculated assuming that the scattered contributions add incoherently at the receiver
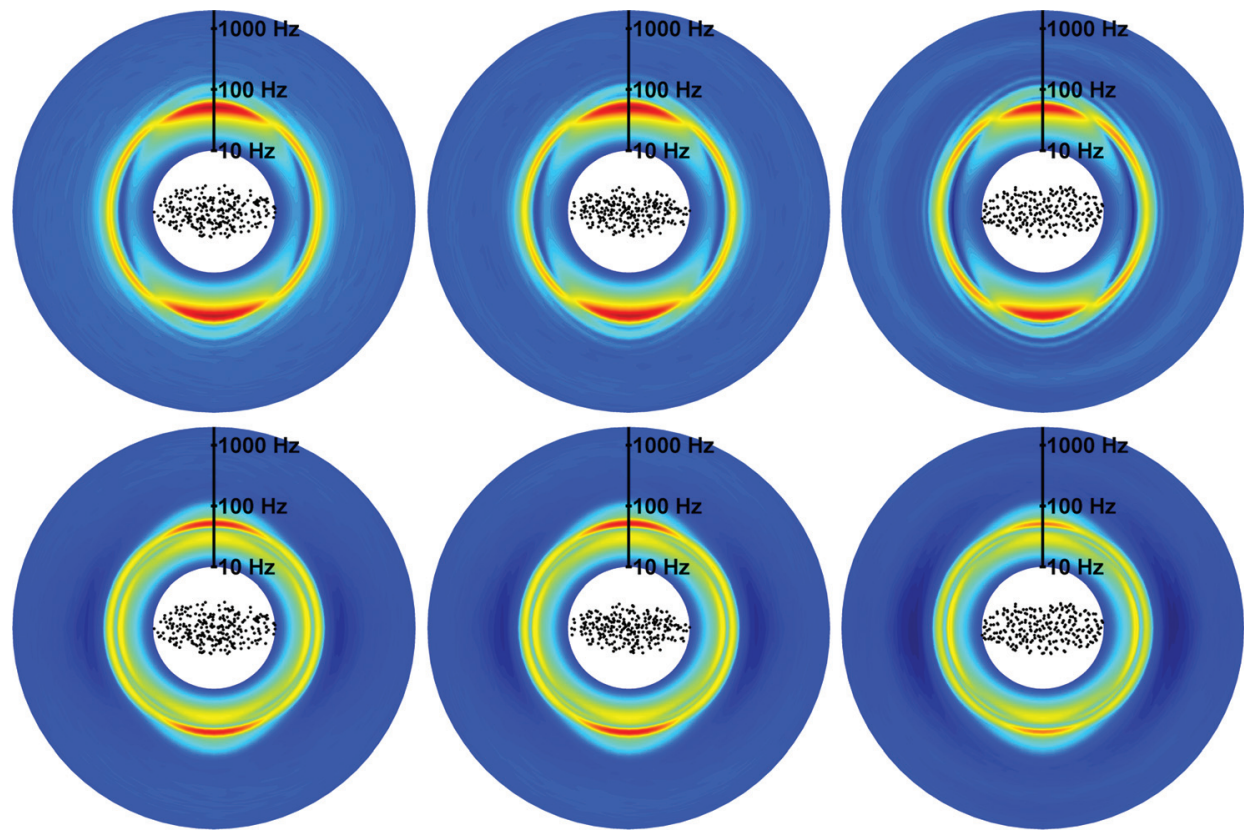

$$
T S_{i n c}=10 \log _{10}\left|\frac{\sum_{i=1}^{263}|p|^{2}}{A^{2}} r^{4}\right| .
$$

In total, seven different school target strength models are considered. This includes six coherent school target strength models: For both single [Eq. (1)] and multiple scattering models [Eq. (4)], fish are distributed with three different degrees of spatial organization (Poisson distributed, a nearest neighbor criterion in range, and a nearest neighbor criterion in both range and bearing). The seventh model includes only incoherent scattering [Eq. (7)] and is independent of spatial organization within the school.

\section{SIMULATION RESULTS}

School target strengths [Eq. (6)] have been calculated as a function of azimuth angle for the three different school models and for both single and multiple scattering as shown in Fig. 7. In all cases, a target strength peak occurs near the swim bladder resonance frequency of $53 \mathrm{~Hz}$. There is also a strong angular dependence in the modeled school target strength with increased backscatter when the school is ensonified along its short axis compared to the model outputs for ensonification along the long axis. This type of angle dependence in the target strength is expected from an ellipsoidal shape [see, for example, Tang (1996), who examined non-spherical bubbles the size of which-normalized by acoustic wavelength - was similar to the school size considered here]. In addition to the angular dependence, large differences in school target strength can be observed between the single and multiple scattering models (Fig. 7, top and bottom rows, respectively). There are also differences in the modeled school target strength related to how the fish are distributed throughout the school (i.e., spatial organization of the fish). The differences related to fish spatial 
organization appear largest when comparing the multiple scattering model results for fish that are Poisson distributed (the lowest level of spatial organization examined) and the fish that are distributed according to a nearest neighbor criteria accounting for both range and bearing (the highest level of spatial organization examined).

To further elucidate the different model results, target strengths for the school when ensonified along both the short and long axis are shown as a function of $k R_{e}$ in Fig. 8. $R_{e}$ is the effective radius of the ellipsoidally shaped school, defined as $R_{e}=\left(3 v_{\text {school }} / 4 \pi\right)^{1 / 3}$ where $v_{\text {school }}$ is the school volume $\left(1900 \mathrm{~m}^{3}\right)$. For all models and at all frequencies, the difference in model results between the Poisson-distributed fish and those distributed accounting for a nearest neighbor criterion in range only is less than $1 \mathrm{~dB}$. For the sake of clarity, Fig. 8 excludes model results corresponding to the latter scenario. From here on, the Poisson distributed fish will be referred to as "unorganized" and the fish distributed with correlations in both range and bearing will be referred to as "organized."

A school resonance corresponding to the average swimbladder resonance frequency $(53 \mathrm{~Hz})$ occurs near $k R_{e}=1.7$. With regard to the level of fish spatial organization incorporated into the model, the largest difference in model results near this resonance occurs when the fish are ensonified along the short axis and multiple scattering is used [Fig. 8(b)]. For this scenario, the modeled school target strength for the unorganized fish are approximately $5 \mathrm{~dB}$ higher than the target strength estimated for the organized fish.

Near the swimbladder resonance frequency, school target strength differences are also evident between the single and multiple scattering models. The difference between single and multiple scattering at the school resonance is most evident when comparing model results corresponding to ensonification along the short axis [Fig. 8(a) vs Fig. 8(b)]. This difference is largest for the organized schools (approximately $7 \mathrm{~dB})$.
A second lower-frequency school resonance occurs near $k R_{e}=1.0(30 \mathrm{~Hz})$ for all school models when the multiple scattering solution is used [Figs. 8(b) and 8(d)]. Evidence of this second resonance is absent for the single scattering models, although for long-axis ensonification [Fig. 8(c)], the single scattering solution shows a weaker resonance near $k R_{e}=0.7(20 \mathrm{~Hz})$. The lower frequency resonance behavior is consistent with the type of school collective resonance described by Hahn (2007), who examined this phenomenon for spherically shaped schools. Using the effective radius $R_{e}$ together with the void fraction of gas associated with the swimbladders comprising the school $\left(1.53 \times 10^{-4}\right)$, the collective resonance frequency is estimated to be $24 \mathrm{~Hz}$ using Hahn's (2007) Eq. (40).

Above the swimbladder resonance frequency, the single scattering model results show evidence of higher order school modes for $k R_{e}>1.0$, particularly for short-axis ensonification [Fig. 8(a)]. These resonances appear to be present in the multiple scattering model results but are muted by comparison to the single scattering model. For ensonification along the long axis of the school, the multiple scattering model results [Fig. 8(d)] between $k R_{e}=2$ and $k R_{e}=10$ for both organized and unorganized schools show a broad decrease in target strength of up to $10 \mathrm{~dB}$ compared to the long-axis single scattering results and a similar decrease in target strength compared to all of the short-axis ensonification model results. All of the school models appear to converge to a target strength of $0 \mathrm{~dB}$ near $2000 \mathrm{~Hz}$

The incoherent target strength model [Eq. (7)] results are within a few decibels of both the single and multiple scattering models near resonance for long-axis ensonification but are lower than these models for short-axis ensonification. Below resonance, the incoherent target strength model deviates substantially from the other models and also does not predict a second low-frequency school resonance. Above resonance, the incoherent target strength model generally
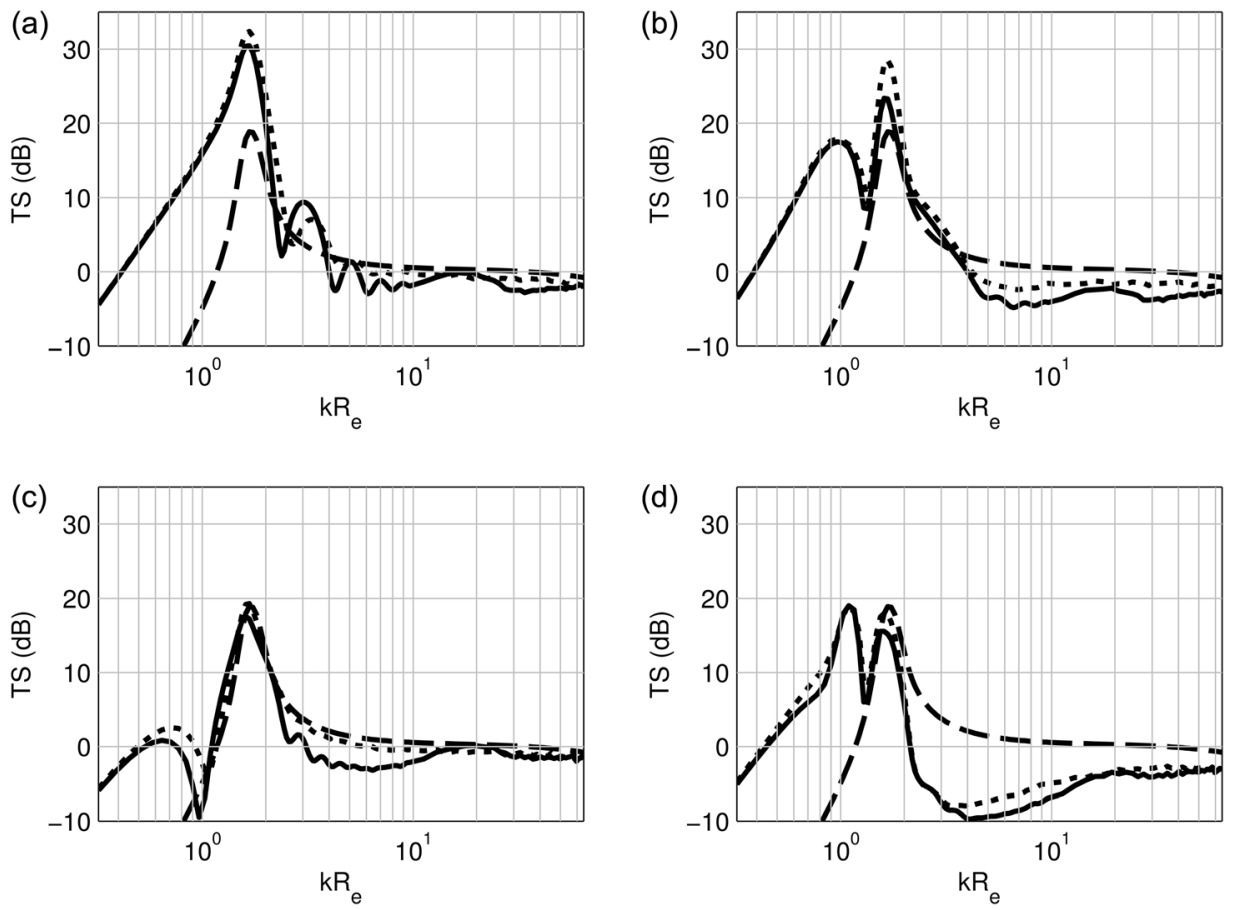

FIG. 8. Target strength as a function of $\mathrm{kR}_{\mathrm{e}}$ for single scattering (left) and multiple scattering (right) solutions) and for ensonification along the short axis (top) and long axis (bottom). Model outputs for the Poisson distributed fish (dotted line) and for the nearest neighbor criterion accounting for both range and bearing (solid line) are shown. The incoherent summation (dashed line) is shown for reference. 
provides a good match with the single scattering model results, although it shows no evidence of the higher order school modes [Figs. 8(a) and 8(c)]. The incoherent target strength model agrees less well with multiple scattering solutions, particularly when considering ensonification along the long axis of the school [Fig. 8(d)] where it provides a target strength estimate that is approximately $10 \mathrm{~dB}$ higher than the other models.

\section{DISCUSSION}

This work is constrained by not having low frequency scattering data from the school with which to compare. To interpret the results, it is assumed that the multiple scattering model [Eq. (4)] more accurately represents the scattering process from the school than the single scattering model [Eq. (1)]. Noting that the multiple scattering model converges to the single scattering model when sound scattering between fish can be neglected, the difference between the two results helps to suggest when it is important to take multiple scattering into account. Further, it is assumed that most accurate model incorporates the greatest amount of information describing the spatial organization of fish within the school. If both of these assumptions are true, then the most accurate model presented in this work is the multiple scattering model for the organized school.

The model results suggest that there is at least a weak dependence of target strength on the spatial organization of fish. For the fish school examined here, the model results indicate that this effect may be observable (approximately $5 \mathrm{~dB}$ ) for target strength measurements collected near the swimbladder resonance when the school was ensonified along its short axis but difficult to observe otherwise (assuming that it is difficult to observe differences of only a few decibels). It is worth noting that ABFT exhibit multiple schooling behaviors and that the modeled results shown here might have differed if, for example, the fish were found in a cartwheel or parabolic school formation frequently exhibited by adult ABFT (Lutcavage and Kraus, 1995). The same is true for other fish that, presumably, exhibit different degrees of spatial organization. Although the work described here does not say anything about these other schools, it does suggest that the spatial organization of fish is worth considering at least for those schools that are highly organized.

Compared to the effects of spatial organization, the results described in this work suggest that it is more important to utilize a multiple scattering model. The largest difference between single and multiple scattering models is the presence of a second resonance below the swim bladder resonance, a result that is consistent with Hahn's results (Hahn, 2007) from multiple scattering from fish schools with high packing densities. Substantial differences between multiple and single scattering solutions can also be found near the swim-bladder resonance ( $7 \mathrm{~dB}$ for organized schools) and above resonance (up to $10 \mathrm{~dB}$ for long-axis ensonification). The differences between single and multiple scattering solutions diminish for all cases at the highest frequencies considered and converge to the results given by the incoherent summation of the scattered waves, suggesting that school scattering has become incoherent at the higher frequencies.

Finally, it is worth repeating that the results of the acoustic scattering models presented here are idealized in that they ignore the presence of boundaries (which were certainly present when the school was observed), ignore any environmental effects (e.g., sound speed variability in the water column) that might alter both the outgoing and returning acoustic waves, and may be difficult to observe in practice due to their very low frequency. These model conditions are perhaps more suitable to other schooling species with smaller swimbladders the resonances of which occur at substantially higher frequencies. However, for smaller species, it is also much more experimentally challenging to observe and resolve the simultaneous positions of individuals within the school. Thus in some sense, the ABFT schools described here might act as a proxy for other schooling, swimbladder bearing fishes. Further, the swimbladder model used here shows a strong dependency on fish length (e.g., a $1 \mathrm{~m}$ fish would have a target strength that is $\sim 9 \mathrm{~dB}$ lower than a $1.5 \mathrm{~m}$ fish, at their respective resonance frequencies). The increase in the scattering strength for the individual scatterers magnifies the difference between the single and multiple scattering solutions (Weber et al., 2007) and, accordingly, would magnify any features seen in the multiple scattering solution that do not appear as strongly when only single scattering is considered. In that sense, the results shown here may represent an end-member case for similarly organized fish with smaller differences associated with spatial organization appearing for smaller fish the swimbladders of which do not radiate as strongly.

\section{ACKNOWLEDGMENTS}

This work was supported by the Office of Naval Research under Grant No. N0014-09-1-0575 to T.W. Additional funding for the field data collection was provided by Northeast Consortium Grant No. 111B12 to M.L., T.W., and others. The authors wish to thank Captain Bill Muniz and Mate Louis Catalina of the F/V Lilly, as well as tuna spotter pilots Mark Brochu and George Purmont, for their expertise in finding schools of ABFT, Sam Greenaway for his assistance with collecting the MBES data, Ben Galuardi, Shachak Pe'eri, and Yuri Rzhanov for their assistance collecting the aerial imagery, and Michele Heller and Katherine Hack for their diligent efforts aimed at manually classifying the aerial imagery. The author's also wish to acknowledge the anonymous reviewers whose comments and suggestions greatly improved this manuscript.

Andrews, M., Gong, Z., and Ratilal, P. (2011). "Effects of multiple scattering, attenuation and dispersion in waveguide sensing of fish," J. Acoust. Soc. Am. 130(3), 1253-1271.

Bertrand, A., Josse, E., and Massé, J. (1999). "In situ acoustic targetstrength measurement of bigeye (Thunnus obesus) and yellowfin tuna (Thunnus albacares) by coupling split-beam echosounder observations and sonic tracking," ICES J. Mar. Sci. 56(1), 51-60.

Brill, B., Lutcavage, M., Metzger, G., Bushnell, P., Arendt, M., Lucy, J., Watson, C., and Foley, D. (2002). "Horizontal and vertical movements of juvenile bluefin tuna (Thunnus thynnus), in relation to oceanographic conditions of the western North Atlantic, determined with ultrasonic telemetry," Fish. Bull. 100, 155-167. 
Carey, W., and Bradley, M. (1985). "Low-frequency ocean surface noise sources," J. Acoust. Soc. Am. 78, S1.

Carey, W., and Fitzgerald, J. (1987). "Low-frequency noise and bubble plume oscillations," J. Acoust. Soc. Am. 82, S62.

Clay, C., and Medwin, H. (1977). Acoustical Oceanography: Principles and Applications (Wiley, New York), pp. 461-465.

Diachok, O. (1999). "Effects of absorptivity due to fish on transmission loss in shallow water," J. Acoust. Soc. Am. 105(4), 2107-2128.

Feuillade, C., Nero, R. W., and Love, R. H. (1996). "A low-frequency acoustic scattering model for small schools of fish,” J. Acoust. Soc. Am. 99(1), 196-208.

Foldy, L. L. (1945). "The multiple scattering of waves," Phys. Rev. 67, 107-119.

Galuardi, B., and Lutcavage, M. (2012). "Dispersal routes and habitat utilization of juvenile Atlantic bluefin tuna, Thunnus thynnus, tracked with mini PSAT and archival tags," PLoS ONE 7(5), e37829, 1-11.

Galuardi, B., Royer, F., Golet, W., Logan, J. M., Neilson, J., and Lutcavage, M. (2010). "Complex migration routes of Atlantic bluefin tuna question current population structure paradigm," Can. J. Fish. Aquat. Sci. 67, 966-976.

Gibbs, R., and Collette, B. (1967). "Comparative anatomy and systematic of the tunas, GENUS THUNNUS," Fish. Bull. 66, 65-130.

Gong, Z., Andrews, M., Jagannathan, S., Patel, R., Jech, J. M., Makris, N. C., and Ratilal, P. (2010). "Low-frequency target strength and abundance of shoaling Atlantic herring (Clupea Harengus) in the Gulf of Maine during the Ocean Acoustic Waveguide Remote Sensing 2006 Experiment," J. Acoust. Soc. Am. 127, 104-123.

Hahn, T. R. (2007). "Low frequency sound scattering from spherical assemblages of bubbles using effective medium theory," J. Acoust. Soc. Am. 122(6), 3252-3267.

Holliday, D. V. (1972). "Resonance structure in echoes from schooled pelagic fish," J. Acoust. Soc. Am. 51, 1322-1332.

Love, R. (1978). "Resonant acoustic scattering by swimbladder-bearing fish,” J. Acoust. Soc. Am. 64, 571-580.

Lutcavage, M., Goldstien, J., and S. Kraus (1997a). "Distribution, relative abundance, and behavior of giant bluefin tuna in New England waters," in 1995 International Commission for the Conservation of Atlantic Tunas, Coll. Vol. Sci SCRS/96/129.

Lutcavage, M., and Kraus, S. (1995). “The feasibility of direct photographic assessment of giant bluefin tuna, Thunnus thynnus, in New England waters," Fish. Bull. 93, 495-503.
Lutcavage, M., Kraus, S., and Hoggard, W. (1997b). "Aerial assessment of giant bluefin tuna in the Bahama Banks-Straits of Florida, 1995," Fish. Bull. 95(2), 300-310.

Lutcavage, M. E., Brill, R., Goldstein, J., Skomal, G., Chase, B., and Tutein, J. (2000). "Movements and behavior of adult North Atlantic bluefin tuna (Thunnus thynnus) in the northwest Atlantic determined using ultrasonic telemetry," Mar. Biol. 137, 347-358.

Magnuson, J. J. (1973). "Comparison study of adaptation for continuous swimming and hydrostatic equilibrium of scombroid and xiphoid fishes," Fish. Bull. 71, 337-356.

Mather, F. J., Mason, J., and Jones, A. (1995). "Historical document: Life history and fisheries of Atlantic Bluefin Tuna," NOAA Technical Memorandum 370 (NOAA, Miami, FL).

Partridge, B., Johansson, J., and Kalish, J. (1983). "The structure of schools of giant bluefin tuna in Cape Cod Bay," Envioron. Biol. Fishes 9, 253-262 (1983).

Pitcher T. J., and Parrish, J. (1993). "Functions of shoaling behavior in teleosts," in Behaviour of Teleost Fishes, edited by T. J. Pithcer (Chapman and Hall, London), pp. 363-439.

Prosperetti, A. (1988). "Bubble-related ambient noise in the ocean," J. Acoust. Soc. Am. 84, 1042-1054.

Restrepo, V., Guillermo, A., Walter, J., Neilson, J., Campana, S., Secor, D., and Wingate, R. (2010). "Updated estimate of the growth curve of Western Atlantic bluefin tuna," Aquat. Living Resour. 23, 335-342.

Schaefer, K., and Oliver, C. (2000). "Shape, volume, and resonance frequency of the swimbladder of yellowfin tuna, Thunnus albacores," Fish Bull. 98, 364-374.

Simmonds, E., and MacLennan, D. (2005). Fisheries Acoustics: Theory and Practice, 2nd ed., (Blackwell Publishing, Oxford), pp. 158-162.

Tang, D. (1996). "Modeling high-frequency acoustic backscattering from gas voids buried in sediments," Geo-Mar. Lett. 16, 261-265.

Weber, T. C., Lyons, A. P., and Bradley, D. L. (2007). "Acoustic propagation through bubble clouds exhibiting spatial structure in the fluctuating number density," IEEE J. Ocean. Eng. 32(2), 513-523.

Weber, T. C., Pena, H., and Jech, J. M. (2009). "Consecutive acoustic observations of an Atlantic herring school in the Northwest Atlantic," ICES J. Mar. Sci. 66, 1270-1277.

Weston, D. E. (1966). "Acoustic interaction effects in arrays of small spheres," J. Acoust. Soc. Am. 29(2), 316-322.

Weston, D. E. (1967). "Sound propagation in the presence of bladder fish," in Underwater Acoustics, edited by V. A. Albers (Plenum, New York), Vol. 2, Chap. 10, p. 196. 